\title{
In vitro modulation of inflammatory target gene expression by a polyphenol- enriched fraction of rose oil distillation waste water
}

Jonas Wedler ${ }^{\mathrm{a}}$, Anna Weston ${ }^{\mathrm{b}}$, Julia Rausenberger ${ }^{\mathrm{c}}$, Veronika Butterweck ${ }^{\mathrm{a}}$,*

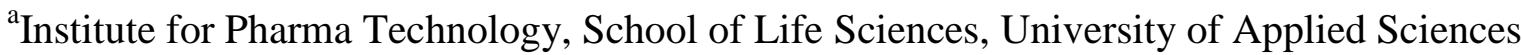
Northwestern Switzerland, Gründenstrasse 40, 4132 Muttenz, Switzerland

${ }^{b}$ Institute for Chemistry and Bioanalytics, School of Life Sciences, University of Applied Sciences Northwestern Switzerland, Gründenstrasse 40, 4132 Muttenz, Switzerland

${ }^{\mathrm{c}}$ School of Life Sciences, University of Applied Sciences Northwestern Switzerland, Gründenstrasse 40, 4132 Muttenz, Switzerland

*Correspondence to:

Prof. Dr. Veronika Butterweck, University of Applied Sciences Northwestern Switzerland, Gründenstrasse 40, 4132 Muttenz, Switzerland, Phone: +41 6146746 89;

Fax: +41 6146747 01, e-mail: veronika.butterweck@fhnw.ch 


\begin{abstract}
Classical production of rose oil is based on water steam distillation from the flowers of Rosa damascena. During this process, large quantities of waste water accrue which are discharged to the environment, causing severe pollution of both, groundwater and surface water due to a high content of polyphenols. We recently developed a strategy to purify the waste water into a polyphenol-depleted and a polyphenol-enriched fraction RF20-(SP-207). RF20-(SP-207) and sub-fraction F(IV) significantly inhibited cell proliferation and migration of HaCaT cells. Since there is a close interplay between these actions and inflammatory processes, here we focused on the fractions' influence on pro-inflammatory biomarkers. HaCaT keratinocytes were treated with RF20-(SP-207), F(IV) (both at $50 \mu \mathrm{g} / \mathrm{mL}$ ) and ellagic acid (10 $\mu \mathrm{M})$ for $24 \mathrm{~h}$ under TNF- $\alpha(20 \mathrm{ng} / \mathrm{mL})$ stimulated and non-stimulated conditions. Gene expression of IL$1 \beta$, IL-6, IL-8, RANTES and MCP-1 was analyzed by reverse transcriptase polymerase chain reaction (RT-PCR) and cellular protein secretion of IL-8, RANTES and MCP-1 was determined by ELISA based assays. RF20-(SP-207) and F(IV) significantly decreased the expression and cellular protein secretion of IL-1 $\beta$, IL-6, IL-8, RANTES and MCP-1. The diminishing effects on inflammatory target gene expression were slightly less pronounced under TNF- $\alpha$ stimulated conditions. In conclusion, the recovered polyphenol fraction RF20(SP-207) from rose oil distillation waste water markedly modified inflammatory target gene expression in vitro, and, therefore, could be further developed as alternative treatment of acute and chronic inflammation.
\end{abstract}

Keywords: Rosa damascena, waste water, anti-inflammatory, RT-PCR, ELISA 


\section{Introduction}

While acute inflammation can be triggered by either foreign microbial invaders or mechanical damage of the skin, chronic inflammation is a result of habitual or environmental factors. By the inflammatory response, the organism tries to defeat the trigger by removing necrotic cells and tissues damaged from the original insult, and thus, to initiate tissue repair [1]. However, in some cases the inflammatory reaction damages the host more than the trigger. Thus, drugs like (non-) steroidal anti-inflammatory drugs (NSAID) have been developed to control the course of the inflammatory response. Considering its complex cascade, not only a cellular crosstalk is crucial, the organism also instantly provides various chemokines and growth factors among others [2]. Some pro-inflammatory constituents of this mixture are the tumor necrosis factor alpha (TNF- $\alpha$ ), IL-1 $\beta$, IL-6, IL-8, Regulated on Activation Normal T-cell Expressed and Secreted (RANTES) and, Monocyte Chemotactic Protein 1 (MCP-1). Taking TNF- $\alpha$ into account, its pivotal role attracted much attention to successfully develop several potent biosimilars [3]. IL-6 promotes inflammation by inducing neovascularization and hyperplasia, which is especially the case for chronic developments [4]. IL-8 is a potent chemoattractant for T lymphocytes, neutrophils and eosinophils [5]. IL-1 $\beta$ levels are usually elevated manifold during progression of auto-immune diseases in particular [6]. As members of the c-c motif family, both RANTES and MCP-1 depict mediators, potent chemo-attractants for macrophages and leukocyte activators [7, 8]. Attenuating or deactivating these agents among others as alternative or improvement to standard drugs is a desirable objective in the treatment of inflammation. In this context, plant derived extracts have gained considerable scientific attention.

Rosa damascena Mill. f. trigintipetala Dieck (Rosaceae) is known for containing a wide spectrum of polyphenols and anthocyanidins. While the oil exerts anti-microbial effects for instance, polyphenols by the majority are responsible for the medicinal properties such as anti-HIV, anti-oxidant, antitussive, anti-diabetic or anti-plasmodia activity [9]. Nowadays, the flowers are annually harvested to extract the essential oil for the cosmetic and food industry [10], whereof about fifty per cent of the global share is produced in Bulgaria [11]. Because of its low content of essential oils $(0.02 \%$ according to Baser et. al. [12]), in each distillation cycle, between 500 and 1000 kilogram of rose petals is used, accruing the four-fold quantity of liquid waste [11]. The volume of production amounts to approximately 1000-2000 kilogram pure rose oil each year. Hence, it not only poses a respectable economic factor, but also a serious environmental damage. Rose oil distillation waste water (RODW) contains hydrophilic polyphenols, which are considered bio-pollutants [13] and thus, is difficult to decompose. However, up-to-date, the by-product is discharged into the drainage system or spread on local soil [14]. For this reason, primarily valorization of a by-product in terms of pharmaceutical beneficence attended by a development of a strategy for wastewater management is one interesting aspect. 
Agents dissolved in rose oil distillation waste water are compounds like kaempferol, quercetin, and ellagic acid and their glycoside derivatives [13, 15-17]. We recently established a strategy to separate RODW into a polyphenol depleted and a polyphenol enriched fraction RF20-(SP-207) [13]. Subsequently, RF20-(SP-207) was submitted to a bioassay-guided fractionation using Sephadex LH20 and was split into four sub-fractions F(I)-(IV) according to their major compounds [17]. Based on our previous results [14], we chose F(IV) for further investigation.

In a former study [14], we reported significant inhibiting effects of RF20-(SP-207) and F(IV) on human keratinocytes in terms of proliferation and migration. Since there exists a close interplay between these cellular processes and events of inflammation [18], the influence on exclusively proinflammatory biomarkers was of interest. Hence, the focus of this study was to explore the effect of RF20-(SP-207) and F(IV) on transcriptional activity of five different key targets in comparison to one of their major single compounds ellagic acid.

\section{Experimental}

\subsection{Chemicals and Reagents}

Ellagic acid (EA, purity $>95 \%$ ) and dimethyl sulfoxide (purity $>99.5 \%$; DMSO) were purchased from Sigma-Aldrich (Buchs, CH). Human IL-8 ELISA kit, Dulbecco's Modified Eagle Medium high glucose (1x), Dulbecco's Phosphate buffered saline without $\mathrm{CaCl}_{2}$ andMgCl 2 , Trypsin-EDTA $0.5 \%$ (10x), 10.000 Units/mL Penicillin and $10.000 \mu \mathrm{g} / \mathrm{mL}$ Streptomycin and heat inactivated calf serum (FCS) were provided by LubioScience (Luzern, CH). E. coli-derived recombinant human TNF-alpha (purity >98\%), human MCP-1 and RANTES ELISA kit were purchased from BioLegend (San Diego, USA).

\subsection{Cell Culture}

Human non-tumorigenic HaCaT keratinocytes (Cell Line Services, Eppelheim, Germany) were maintained in Dulbecco's Modified Eagle's Medium high glucose 1x supplemented with 1\% (v/v) Penicillin $10.000 \mathrm{U} / \mathrm{mL} /$ Streptomycin $10.000 \mu \mathrm{g} / \mathrm{mL}$ and 10\% (v/v) heat inactivated fetal calf serum (FCS) at $37{ }^{\circ} \mathrm{C}$ in a humidified atmosphere containing $5 \% \mathrm{CO}_{2}$. Experiments were routinely conducted at approximately 80-90\% confluency [19] and carried out between passages 55 and 67. Both, RF20(SP-207) and F(IV) were tested in a concentration of $50 \mu \mathrm{g} / \mathrm{mL}$, while ellagic acid was used at $10 \mu \mathrm{M}$. Additionally, the substances were individually applied in the same concentrations with a supplementation of $20 \mathrm{ng} / \mathrm{mL}$ TNF- $\alpha$. This set-up was used to simulate an in vitro inflammatory condition. The results of each experiment were compared to an untreated control signifying keratinocytes exposed to medium with $0 \%$ serum, and a treated control composed of medium with 20 $\mathrm{ng} / \mathrm{mL}$ TNF- $\alpha$. Except ellagic acid (DMSO concentration $0.125 \%$ ), all compounds were used in a final 
DMSO concentration of max. $0.1 \%(\mathrm{v} / \mathrm{v})$, which has been proven harmless for this cell line (data not shown).

\subsection{Plant Material and Extract Preparation}

Wastewater obtained after distillation of full-blown $R$. damascena flowers was obtained from the distillery of the Institute of Roses, Essential and Medicinal Crops (IREMC) in Kazanlak, Bulgaria, in June 2013. RF20-207 was prepared from RODW as described previously [13]. Briefly, the concentration process includes a filtration process to eliminate suspended solids in the wastewater, followed by adsorption of phenolic compounds from RODW onto adsorption resins (XAD and SP). Finally, desorption of the polyphenol fraction from the resin matrix was achieved using ethanol and/or aqueous ethanol. The result of the process was a wastewater low in soluble organic compounds and an enriched polyphenol fraction (RF20-(SP-207)). The profile of RF20-(SP-207) was similar to that of RODW, and showed the presence of flavonols such as quercetin and kaempferol glycosides as major metabolites [13]. Fractions (I)-(IV) were obtained and phytochemical characterized as described in [17]. Extensive phytochemical descriptions of RF20-207 and F(IV) is published in [13, 17]. RF20(SP-207) mainly consisted of phenolic compounds, such as isoquercitrin, kaempferol, quercitrin, rutin, astragalin, multiflorin A, ellagic acid and several kaempferol and quercetin glycosides [13]. F(IV) mainly consisted of ellagic acid, quercetin and kaempferol [17]. A voucher specimen of rose oil distillation waster water (\#RODW_June2013) is stored at $-20^{\circ} \mathrm{C}$ at the Institute for Pharma Technology, School of Life Sciences, FHNW.

\subsection{RNA and Real Time Quantitative RT-PCR}

After cell treatment and incubation in 12-well plates, mRNA was extracted using the RNEasy Mini Kit by Qiagen (Valencia, USA). Subsequently, mRNA concentration was measured at $260 \mathrm{~nm}$ using the NanoDROP 2000c Spectrometer (Thermo Fischer Scientific) and samples were diluted accordingly to a final concentration of $6 \mathrm{ng} / \mu \mathrm{L}$. Reverse transcription was done in two steps utilizing the Biometra T3000 Thermocycler (Göttingen). First, $66 \mathrm{ng}$ of RNA were charged with $80 \mathrm{ng}$ Oligo-dT primers/reaction (Qiagen) and incubated for $5 \mathrm{~min}$ at $70{ }^{\circ} \mathrm{C}$. Immediately after adding a solution containing 200 units of M-MLV reverse transcriptase 1x buffer (Promega) and $0.5 \mathrm{mM}$ of each dNTP (Solis Biodyne), reverse transcription was continued by incubation for one hour at $37{ }^{\circ} \mathrm{C}$. After retrieval of the cDNA, control and samples were mixed with the TaqMan Gene Expression assay probes (Thermo Fischer Scientific) and Faststart TaqMan Probe Master Mix (Roche Diagnostics) according to the manufacturer's instructions. cDNA was amplified in a Corbett Rotor-Gene 6000 (Qiagen). An initial denaturation of $10 \mathrm{~min}$ at $95^{\circ} \mathrm{C}$ was followed by 40 cycles of $15 \mathrm{sec}$ at $95{ }^{\circ} \mathrm{C}$ and one min. at $60{ }^{\circ} \mathrm{C}$. Fluorescence was detected at $510 \mathrm{~nm}$ and data were collected using the "Rotor 
Gene Q - Pure Detection" Software (v. 2.3.1). All values were normalized to the expression of the housekeeping gene Glycerinaldehyd-3-phosphat-Dehydrogenase (GAPDH).

\subsection{Measurement of IL-8, RANTES, MCP-1 Secretion}

The experimental setup including the TNF- $\alpha$ concentration was chosen according to Park et al. [20], with some modifications. For the samples and controls, cells were seeded into 12-well plates at a density of $1.5 \times 10^{5}$ cells $/ \mathrm{mL}$. After an incubation time of 24 hours $\left(37{ }^{\circ} \mathrm{C}, 5 \% \mathrm{CO} 2\right)$, DMEM with $10 \%$ $(\mathrm{v} / \mathrm{v})$ serum was discarded, cells were washed with one $\mathrm{mL} /$ well PBS and medium was exchanged to DMEM containing 0\% FCS or the test solutions plus $20 \mathrm{ng} / \mathrm{mL}$ TNF- $\alpha$. The second 24-hour period happened under the same conditions. Protein levels obtained from the untreated control are regarded as the basal secretion of the designated target in keratinocytes. In the end, supernatants were aspirated, stored in sterile micro centrifuge tubes and deep-frozen $\left(-20{ }^{\circ} \mathrm{C}\right)$ immediately. Absorbance was measured at $450 \mathrm{~nm}$ using a microplate reader (Spectramax i3x Multimode detection platform, Molecular Devices).

\subsection{Statistical Analysis}

Data are shown as mean \pm standard deviation (SD). ELISA experiments were performed in triplicates; each experiment was repeated at least three times (on different days). The protein levels were then calculated according to a standard curve. PCR experiments were executed in duplicates, a sample and one technical replicate; experiments were repeated at least five times (on different days). Results were processed according to the comparative $\mathrm{C}_{\mathrm{T}}$ Method $\left(\Delta \Delta \mathrm{C}_{\mathrm{T}}\right.$-Method;

http://www3.appliedbiosystems.com/cms/groups/mcb_support/documents/generaldocuments/cms_042 380.pdf) by the following equations using Microsoft Excel 2013 :

$$
-\left(\begin{array}{ll}
\Delta & s
\end{array}\right)
$$

To process the results by the comparative $\mathrm{C}_{\mathrm{T}}$ Method, the replication efficiency of the housekeeping gene and the targets have to be equal. The manufacturer of the TaqMan gene expression assays (Applied Biosciences) guarantees an amplification efficiency close to $100 \%$ 
(http://www3.appliedbiosystems.com/cms/groups/mcb_marketing/documents/generaldocuments/cms_ 040377.pdf). The term "down-regulation" refers to a gene expression level below the untreated control $(<1)$, whereas "up-regulation" describes a level $>1$. Further statistical analysis was carried out by oneway analysis of variance (ANOVA) followed by Dunnett's multiple comparison test using the software package GraphPad Prism (version 6.01, GraphPad Software Inc.). In all cases, differences were considered significant if $\mathrm{p}$ was below 0.05 .

\section{Results}

\subsection{Gene Expression Inhibitory Activities of RF20-(SP-207), F(IV) and Ellagic Acid}

As a first step, the target-specific $\mathrm{C}_{\mathrm{T}}$-values of cells treated by RF20-(SP-207), $\mathrm{F}(\mathrm{IV}$ ) (both $50 \mu \mathrm{g} / \mathrm{mL}$ ) and ellagic acid at $10 \mu \mathrm{M}$ were detected, calculated to fold changes and compared to the control

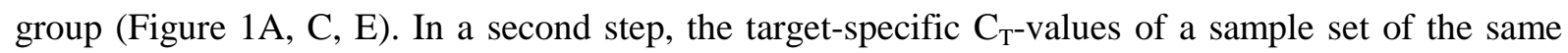
substances each stimulated with $20 \mathrm{ng} / \mathrm{mL}$ TNF- $\alpha$ was obtained (Figure 1B, D, F). This set-up was used to simulate an inflammation state scenario in vitro.

Figure 1 A reveals a significant ( $\mathrm{p}<0.001), 4.8$-fold IL-1 $\beta$-gene expression in the TNF- $\alpha$ stimulated group compared to the control group. However, there was no significant difference between the control group and the groups treated with the test substances., Figure $1 \mathrm{~B}$ shows that all substances significantly $(\mathrm{p}<0.001)$ reduced the IL-1 $\beta$-gene expression level ranging between 20 -fold for RF20(SP-207) and 10-fold for ellagic acid compared to 90-fold of the stimulated control when they were concomitantly applied with $20 \mathrm{ng} / \mathrm{mL}$ TNF- $\alpha$.

Figure 1C displays that addition of TNF- $\alpha$ significantly increased IL-8 gene expression while the expression of IL-8 for RF20-(SP-207), F(IV) and ellagic acid remained on control level. When all test substances where concomitantly applied with TNF- $\alpha$, the gene expression of IL- 8 was significantly downregulated if compared to the TNF- $\alpha$ group alone (Figure 1D)

It was of further interest to determine if RF20-(SP-207) or F(IV) have an effect on the transcriptional activity of IL-6. Neither RF20-(SP-207) nor F(IV) revealed a significant divergence compared to the unstimulated control (Figure 1E). When cells were stimulated with TNF- $\alpha$ - a 5-fold increase in IL_6 gene expression was observed (Figure 1 F).. Interestingly, this increase could only be blocked by F(IV) when concomitantly applied with TNF- $\alpha$-. It has to be mentioned that the relative stimulation of the IL- 6 transcription by the stimulated control was not as strong as the fold changes of stimulated controls tested for the other targets. The fold-change of ellagic acid exceeded that of the TNF- $\alpha$ group clearly (9-fold vs. 5-fold), while RF20-(SP-207) remained on the level of the TNF- $\alpha$ group(Figure 1F). Considering RANTES, the TNF- $\alpha$-boosted control caused a significant $(p<0.001)$ stimulation in gene expression (14.5-fold, Figure $2 \mathrm{~A}$ ), while this was not the case for the unstimulated agents. The $2^{-\Delta \Delta \mathrm{CT}}$ values of RF20-(SP-207) and F(IV) remained at 1.5-fold and 1.6-fold, respectively. Merely the value of the ellagic acid-treated sample was slightly higher with 2.6 in fold change, however, not 
significantly different to the unstimulated control. This ratio is comparable to the TNF- $\alpha$-stimulated set-up (Figure 2 B). In contrast to a 50-fold up-regulation of the boosted control, the extract and its fraction decreased the RANTES-gene-expression to 6.6- and 5.6-fold, respectively. This diminishing effect was weaker under influence of ellagic acid (18-fold expression). Nevertheless, all stimulated substances caused significant $(\mathrm{p}<0.001)$ reducing effects.

Containing a c-c motif, MCP-1 belongs to the same family like RANTES. In both experimental setups, an intensive, significant $(\mathrm{p}<0.001)$ up-regulation of the stimulated control could be detected (Figure $2 \mathrm{C}$ and D; 100 and 417-fold, respectively). Ellagic acid and F(IV) were determined at a 0.7and 0.8 -fold change and therefore generated a weak down-regulation (Figure $2 \mathrm{C}$ ). With a fold-change of 1, RF20-(SP-207) did not alter transcriptional activity compared to the untreated control. In contrast, fold-changes in the inflamed set-up were detected elevated (Figure $2 \mathrm{D}$ ). Nonetheless, $2^{-\Delta \Delta \mathrm{CT}}$ values of the three substances were discovered to be significantly $(\mathrm{p}<0.001)$ reduced compared to the stimulated control with a 417-fold expression increase. Among the three sample agents, the expression-rate of F(IV) were detected at 58-fold, ellagic acid at 97-fold and RF20-(SP-207) at 149fold.

\subsection{Protein Secretion of IL-8, RANTES and MCP-1}

To investigate potential correlations of gene expression with protein secretion, IL-8, RANTES and MCP-1 were selected as biomarkers for ELISA-based assays. Comparability was ensured by choosing the same setting (unstimulated/stimulated) like in previous experiments.

With $543 \mathrm{pg} / \mathrm{mL}$, the IL-8 production in HaCaT keratinocytes was significantly $(\mathrm{p}<0.001)$ increased in the TNF- $\alpha$-stimulated control (Figure 3 A). The levels of unstimulated samples ranged between 2.6 $\mathrm{pg} / \mathrm{mL}$ for $\mathrm{F}(\mathrm{IV})$ and $7.8 \mathrm{pg} / \mathrm{mL}$ for ellagic acid. Yielding $8.3 \mathrm{pg} / \mathrm{mL}$, the unstimulated control was negligibly higher. Cells under influence of TNF- $\alpha$ plus the particular substance secreted higher amounts of IL-8 with exception of F(IV). The addition of $50 \mu \mathrm{g} / \mathrm{mL}$ RF20-(SP-207) resulted in a protein level of $48 \mathrm{pg} / \mathrm{mL}$, which relates to less than $10 \%$ of the level secreted by the stimulated control. Ellagic acid $+\mathrm{TNF}-\alpha$ caused a secretion level of $175 \mathrm{pg} / \mathrm{mL}$ relating to $32 \%$ protein concentration of the stimulated control. However, all tested agents were capable to decrease the protein secretion significantly $(\mathrm{p}<0.001)$.

By executing the ELISA assay detecting the RANTES release, it could be demonstrated that all tested agents possessed significant $(p<0.001)$ decreasing properties on protein secretion compared to the stimulated control except ellagic acid supplemented with $20 \mathrm{ng} / \mathrm{mL}$ TNF- $\alpha$ (Figure $3 \mathrm{~B}$ ). While all levels were in line with the unstimulated control (approx. $4 \mathrm{pg} / \mathrm{mL}$ RANTES), ellagic acid + TNF- $\alpha$ generated a protein raise up to $25.9 \mathrm{pg} / \mathrm{mL}$, which was slightly higher than the stimulated control (23.4 $\mathrm{pg} / \mathrm{mL})$.

The characteristics of RF20-(SP-207), F(IV) and ellagic acid were finalized by conducting the ELISA assay indicating MCP-1 as a biomarker (Figure 3C). In the unstimulated set-up, the concentrations 
under influence of each treatment accordingly did not alter significantly from the unstimulated control (approx. $10 \mathrm{pg} / \mathrm{mL} \mathrm{MCP-1).} \mathrm{However,} \mathrm{the} \mathrm{inflamed} \mathrm{scenario} \mathrm{displayed} \mathrm{a} \mathrm{different} \mathrm{picture.} \mathrm{While}$ treatment with $50 \mu \mathrm{g} / \mathrm{mL}$ of F(IV) caused a reduction of the protein level to $24 \mathrm{pg} / \mathrm{mL}$ MCP-1, RF20(SP-207) reduced to an average of only $211 \mathrm{pg} / \mathrm{mL}$. This value correlates to $9.5 \%$ of the stimulated control and therefore also results in a significant $(\mathrm{p}<0.001)$ decrease. Exceptionally the treatment of ellagic acid + TNF- $\alpha$ did not decrease the MCP-1 level. Interestingly, yielding $2490 \mathrm{pg} / \mathrm{mL}$ in average, it mildly outperformed the stimulated control. Regarding the ELISA-based results, the commonality of all of them is the surprisingly elevated protein level under influence of $10 \mu \mathrm{M}$ ellagic acid supplemented with $20 \mathrm{ng} / \mathrm{mL}$ TNF- $\alpha$.

\section{Discussion}

In a previous study [14], we discovered a pronounced inhibitory effect of RF20-(SP-207) and F(IV) on human keratinocytes regarding proliferation and migration. Cellular reproduction and locomotive actions are closely related to events of inflammation [18]. Thus, the focus of this study was to explore the effect of RF20-(SP-207) and F(IV) on transcriptional activity of five different pro-inflammatory key targets in comparison to ellagic acid. As a follow-up investigation, three of these targets were examined in respect of their protein secretion.

With IL-1 $\beta$, IL-6, and IL-8 playing pivotal roles in events of inflammation [21-23], their differential gene modulation under influence of polyphenols were of interest. In this regard, numerous publications highlight the suppressive effects of flavonoids. For instance, Cho et. al. [24] reported a down-regulation of transcriptional activity of IL-1B and IL-6 by treating RAW 264.7 cells with various concentrations of quercetin in a dose- and time-dependent fashion. Min et. al. [25] exposed HMC-1 cells to quercetin and observed down-regulation of the gene expression of IL-1ß, IL- 6 and IL8. Albeit research is currently ongoing, one mechanism of these effects is discussed to occur by quercetin blocking the transcription factor NF-KB [26-28] and other serine/threonine kinases like the p38 mitogen activated protein kinase [25, 29]. Quercetin, kaempferol, ellagic acid and their derivatives are major compounds in RF20-(SP-207), as well as in its sub-fraction (for compound analysis, see [17]). Despite differences in the cell line and mode of stimulation, the findings of the present study are widely in accordance with the literature within the meaning of IL-1ß, IL-6 and IL-8 gene expression modulation . However, the detection of a down-regulation of IL-1 $\beta$ and IL-8 gene expression by ellagic acid $+\mathrm{TNF}-\alpha$ compared to an increased protein secretion for the same targets was not as uniform as results obtained for RF20-(SP-207) and F(IV) for these targets . Kemp et. al. [30] analyzed cytokine expression levels in epithelial cells of human cervical tissue and found homogenous results for IL-8, but heterogeneous values for IL-6, which indicates a natural variance of the target. Nevertheless, our results of both, the transcriptional activity and the protein secretion, correlate for RF20-(SP-207) and F(IV) on IL-8, RANTES and MCP-1. 
RANTES and MCP-1 are chemokines with a chemotactic mode of action for various cell types and therefore, they are related in their mechanism [31]. For example, as a c-c motif member, RANTES recruits leukocytes to the site of action under the conditions of chronic inflammation [32]. Less extensive literature exists about the gene modulation of these two biomarkers under influence of polyphenols. Fukushima et al. [33] conducted a DNA microarray on HMC-1 human mast cells after exposition of ellagic acid/quercetin containing Drosera species and demonstrated a down-regulation of these two biomarkers, IL-8 and IL-6 among others. It was shown that Drosera species containing the highest amount of ellagic acid and the lowest amount of quercetin induced the highest value of fold change [33]. Taking these facts into account, our data correlate with these published data and an involvement of the individual flavonoids present in RF20-(SP-207) and F(IV) on differential gene modulation can be assumed.

Polyphenols, particularly flavonoids are known to have synergistic properties [34-38]. Ellagic acid as a pure compound in combination with TNF- $\alpha$ revealed weak anti-inflammatory potential on our selection of targets, whereas concomitant application of TNF- $\alpha$ and RF20-(SP-207) and its subfraction F(IV) possessed clear antiinflammatory properties in a comparable manner. Thus, in light of the aforementioned literature and the present data, a synergism of polyphenolic compounds in the fraction RF20-(SP-207), as well as in the sub-fraction F(IV) is assumed.

\section{Conclusion}

In summary, RF20-(SP-207), a polyphenol enriched fraction of RODW, demonstrated potent tyrosinase inhibiting properties. Ellagic acid which was in our previous study identified as a compound being responsible for the potent tyrosinase inhibitory effects [17], could not alone explain the anti-inflammatory effects of RF20-(SP-207) and F(IV) in the present study. Interestingly, the activities on target gene expression and protein secretion levels of RF20-(SP-207) and F(IV) were comparable suggesting that there are further unknown compounds in RF20-(SP-207) and fraction IV which possess anti-inflammatory activities.

Research on anti-inflammatory properties of flavonoids and their mechanism has been extensively reviewed in the literature. One favored approach is the analysis of the polyphenols' effect on transcription factors like NF-kB or serine/threonine proteases, thereof possible downstream effects are then inferred. By focusing on very specific downstream targets that play pivotal roles in the direct inflammatory response, we illustrated the anti-inflammatory potential of RF20-(SP-207) and suggest this polyphenol-enriched fraction as a promising candidate for the treatment of acute and chronic inflammation. By valorization of a by-product of the rose oil production, these findings also might be relevant for the establishment of a waste water management. 


\section{Acknowledgements}

This project was financially supported by the Swiss National Science Foundation (SNF), project number IZEBZ0_143110 / 1 and the Ministry of Education and Science of Bulgaria - Project D021148 within the frame of the Bulgarian-Swiss Research Program 2011-2016. We thank Prof. Dr. Ivan Atanassov and Prof. Dr. Krasimir Rusanov, AgroBio Institute, Sofia, Bulgaria for providing us with RF20-SP207 and FIV.

\section{Figure Legend}

Figure 1: Transcriptional activity of selected chemokines in HaCaT keratinocytes under influence of RF20-(SP-207) $(50 \mu \mathrm{g} / \mathrm{mL}), \mathrm{F}(\mathrm{IV})(50 \mu \mathrm{g} / \mathrm{mL})$ and ellagic acid $(10 \mu \mathrm{M})$. A fold change of IL-1 $\beta$ expression; B fold change of IL-1 $\beta$ with substances supplemented with TNF- $\alpha(20 \mathrm{ng} / \mathrm{mL})$; C fold change of IL-8 expression; D fold change of IL-8 expression with substances supplemented with TNF$\alpha(20 \mathrm{ng} / \mathrm{mL}) ; \mathbf{E}$ fold change of IL-6 expression; $\mathbf{F}$ fold change of IL-6 expression with substances supplemented with TNF- $\alpha(20 \mathrm{ng} / \mathrm{mL})$. Data expressed as Mean $\pm \mathrm{SD}$ of $2^{-\Delta \Delta C_{T}}$. N $\geq 3$ independent experiments. A, C, $\mathbf{E} * * * \mathrm{p}<0.001$ vs. Control; $\mathbf{B}, \mathbf{D}, \mathbf{F} * \mathrm{p}<0.1, * * * \mathrm{p}<0.001$ vs. Control + TNF- $\alpha$.

Figure 2: Transcriptional activity of selected chemokines in $\mathrm{HaCaT}$ keratinocyte under influence of RF20-(SP-207) $(50 \mu \mathrm{g} / \mathrm{mL}), \mathrm{F}(\mathrm{IV})(50 \mu \mathrm{g} / \mathrm{mL})$ and ellagic acid $(10 \mu \mathrm{M})$. A fold change of RANTES expression; B fold change of RANTES expression with substances supplemented with TNF- $\alpha$ (20 $\mathrm{ng} / \mathrm{mL}$ ); D fold change of MCP-1 expression; $\mathbf{E}$ fold change of MCP-1 expression with substances supplemented with TNF- $\alpha(20 \mathrm{ng} / \mathrm{mL})$. Data expressed as Mean $\pm \mathrm{SD}$ of $2^{-\Delta \Delta C_{T}} . \mathrm{N} \geq 3$ independent experiments. A, B $* * * p<0.001$ vs. Control; C, D ***p $<0.001$ vs. Control + TNF- $\alpha$.

Figure 3: Differential regulation of ELISA-based protein secretion in HaCaT keratinocytes under influence of RF20-(SP-207) $(50 \mu \mathrm{g} / \mathrm{mL}), \mathrm{F}(\mathrm{IV})(50 \mu \mathrm{g} / \mathrm{mL})$ and ellagic acid $(10 \mu \mathrm{M})$ with and without supplementation of TNF- $\alpha$ (20 ng/mL). A IL-8 secretion; B RANTES secretion; C MCP-1 secretion. Data expressed as Mean \pm SD. $\mathrm{N} \geq 3$ independent experiments. ${ }^{* * *} \mathrm{p}<0.001$ vs. Control $+\mathrm{TNF}-\alpha$. $\# \#$ p $<0.001$ vs. Control. 


\section{References}

[1] Garcia-Lafuente, A, Guillamon, E, Villares, A, Rostagno, MA, Alfredo Martinez, J. Flavonoids as anti-inflammatory agents: implications in cancer and cardiovascular disease. Inflamm. Res. 58 (2009) 537-552.

[2] Martin, P, Leibovich, SJ. Inflammatory cells during wound repair: the good, the bad and the ugly. Trends Cell Biol. 15 (2005) 599-607.

[3] Levin, AD, Wildenberg, ME, van den Brink, GR. Mechanism of action of anti-tnf therapy in inflammatory bowel disease. J. Crohns Colitis 10 (2016)989-97.

[4] Lubrano, E, Perrotta, FM. Beyond tnf inhibitors: new pathways and emerging treatments for psoriatic arthritis. Drugs 76 (2016) 663-673.

[5] Schmidt, E, Ambach, A, Bastian, B, Brocker, EB, Zillikens, D. Elevated levels of interleukin-8 in blister fluid of bullous pemphigoid compared with suction blisters of healthy control subjects. J. Am. Acad. Dermatol. 34 (1996) 310-312.

[6] Dinarello, CA. Interleukin-1 in the pathogenesis and treatment of inflammatory diseases. Blood 117 (2011) 3720-3732.

[7] Appay, V, Rowland-Jones, SL. RANTES: a versatile and controversial chemokine. Trends Immunol. 22 (2001) 83-87.

[8] Ito, A, Suganami, T, Yamauchi, A, Degawa-Yamauchi, M, Tanaka, M, Kouyama, R, Kobayashi, Y, Nitta, N, Yasuda, K, Hirata, Y, Kuziel, WA, Takeya, M, Kanegasaki, S, Kamei, Y, Ogawa, Y. Role of cc chemokine receptor 2 in bone marrow cells in the recruitment of macrophages into obese adipose tissue. J. Biol. Chem. 283 (2008) 35715-35723.

[9] Boskabady, MH, Shafei, MN, Saberi, Z, Amini, S. Pharmacological effects of Rosa damascena. Iran. J. Basic Med. Sci. 4 (2011) 295 - 307.

[10] Baydar, H, Baydar, NG. The effects of harvest date, fermentation duration and tween 20 treatment on essential oil content and composition of industrial oil rose (Rosa damascena Mill.). Ind. Crops Prod. 21 (2005) 251-255.

[11] Kovacheva, N, Rusanov, K, Atanassov, I. Industrial cultivation of oil bearing rose and rose oil production in Bulgaria during 21(St) century, directions and challenges. Biotechnol. Biotechnol. Equip. 24 (2010) 1793 - 1798.

[12] Baser, KHC, Kurkcuoglu, M, Ozek, T. Turkish rose oil: Recent results. Perf. Flavour. 28 (2003) 3442.

[13] Rusanov, K, Garo, E, Rusanova, M, Fertig, O, Hamburger, M, Atanassov, I, Butterweck, V. Recovery of polyphenols from rose oil distillation wastewater using adsorption resins--a pilot study. Planta Med. 80 (2014) 1657-1664. 
[14] Wedler, J, Rusanov, K, Atanassov, I, Butterweck, V. A polyphenol-enriched fraction of rose oil distillation wastewater inhibits cell proliferation, migration and TNF-alpha-induced VEGF secretion in human immortalized keratinocytes. Planta Med. 82 (2016) 1000-1008.

[15] Schiber, A, Mihalev, K, Berardini, N, Mollov, P, Carle, R. Flavonol glycosides from distilled petals of Rosa damascena Mill. Z. Naturforsch. 60 (2005) 379-84.

[16] Mahmood, N, Piacente, S, Pizza, C, Burke, A, Khan, AI, Hay, AJ. The anti-hiv activity and mechanisms of action of pure compounds isolated from Rosa damascena. Biochem. Bioph. Res. Commun. 229 (1996) 73-79.

[17] Solimine, J, Garo, E, Wedler, J, Rusanov, K, Fertig, O, Hamburger, M, Atanassov, I, Butterweck, V. Tyrosinase inhibitory constituents from a polyphenol enriched fraction of rose oil distillation wastewater. Fitoterapia 108 (2016) 13-19.

[18] Jackson, JR, Seed, MP, Kircher, CH, Willoughby, DA, Winkler, JD. The codependence of angiogenesis and chronic inflammation. FASEB J. 11 (1997) 457-465.

[19] Boukamp, P, Petrussevska, RT, Breitkreutz, D, Hornung, J, Markham, A, Fusenig, NE. Normal keratinization in a spontaneously immortalized aneuploid human keratinocyte cell-line. Int. J. Cell Biol. 106 (1988) 761-771.

[20] Park, K, Lee, JH, Cho, HC, Cho, SY, Cho, JW. Down-regulation of il-6, il-8, tnf-alpha and il-1 beta by glucosamine in hacat cells, but not in the presence of tnf-alpha. Oncol. Lett. 1 (2010) 289-92. [21] Palomino, DCT, Marti, LC. Chemokines and immunity. Einstein (Sao Paulo) 13 (2015) 469-73. [22] Feldmeyer, L, Werner, S, French, LE, Beer, HD. Interleukin-1, inflammasomes and the skin. Eur. J. Cell Biol. 89 (2010) 638-644.

[23] Fonseca, JE, Santos, MJ, Canhao, H, Choy, E. Interleukin-6 as a key player in systemic inflammation and joint destruction. Autoimmun. Rev. 8 (2009) 538-542.

[24] Cho, SY, Park, SJ, Kwon, MJ, Jeong, TS, Bok, SH, Choi, WY, Jeong, WI, Ryu, SY, Do, SH, Lee, CS, Song, JC, Jeong, KS. Quercetin suppresses proinflammatory cytokines production through map kinases and nf-kappa b pathway in lipopolysaccharide-stimulated macrophage. Mol. Cell Biochem. 243 (2003) 153-160.

[25] Min, YD, Choi, CH, Bark, H, Son, HY, Park, HH, Lee, S, Park, JW, Park, EK, Shin, HI, Kim, SH. Quercetin inhibits expression of inflammatory cytokines through attenuation of nf-kappa $\mathrm{b}$ and p38 mapk in hmc-1 human mast cell line. Inflamm. Res. 56 (2007) 210-215.

[26] Crespo, I, Garcia-Mediavilla, MV, Gutierrez, B, Sanchez-Campos, S, Tunon, MJ, GonzalezGallego, J. A comparison of the effects of kaempferol and quercetin on cytokine-induced proinflammatory status of cultured human endothelial cells. Br. J. Nutr. 100 (2008) 968-976.

[27] Weng, Z, Zhang, B, Asadi, S, Sismanopoulos, N, Butcher, A, Fu, X, Katsarou-Katsari, A, Antoniou, C, Theoharides, TC. Quercetin is more effective than cromolyn in blocking human mast cell cytokine release and inhibits contact dermatitis and photosensitivity in humans. Plos One 7 (2012) e33805. 
[28] Nair, MP, Mahajan, S, Reynolds, JL, Aalinkeel, R, Nair, H, Schwartz, SA, Kandaswami, C. The flavonoid quercetin inhibits proinflammatory cytokine (tumor necrosis factor alpha) gene expression in normal peripheral blood mononuclear cells via modulation of the nf-kappa beta system. Clin. Vaccine Immunol. 13 (2006) 319-328.

[29] Middleton, E, Kandaswami, C. Effects of flavonoids in immune and inflammatory cell functions. Biochem. Pharmacol. 43 (1992) 1167-1179.

[30] Kemp, B, Menon, R, Fortunato, SJ, Winkler, M, Maul, H, Rath, W. Quantitation and localization of inflammatory cytokines interleukin- 6 and interleukin- 8 in the lower uterine segment during cervical dilatation. J. Assist. Reprod. Genet. 19 (2002) 215-219.

[31] Conti, P, DiGioacchino, MD. MCP-1 and RANTES are mediators of acute and chronic inflammation. Allergy Asthma Proc. 22 (2001) 133-137.

[32] Proudfoot, AE. Chemokine receptors: multifaceted therapeutic targets. Nat. Rev. Immunol. 2 (2002) 106-115.

[33] Fukushima, K, Nagai, K, Hoshi, Y, Masumoto, S, Mikami, I, Takahashi, Y, Oike, H, Kobori, M. Drosera rotundifolia and drosera tokaiensis suppress the activation of hmc-1 human mast cells. J. Ethnopharmacol. 125 (2009) 90-96.

[34] Georgiev, V, Ananga, A, Tsolova, V. Recent advances and uses of grape flavonoids as nutraceuticals. Nutrients 6 (2014) 391-415.

[35] Kumar, S, Pandey, AK. Chemistry and Biological Activities of Flavonoids: An overview. The Scientific World Journal 2013 (2013) Article ID 162750.

[36] Herranz-Lopez, M, Fernandez-Arroyo, S, Perez-Sanchez, A, Barrajon-Catalan, E, Beltran-Debon, R, Abel Menendez, J, Alonso-Villaverde, C, Segura-Carretero, A, Joven, J, Micol, V. Synergism of plant-derived polyphenols in adipogenesis: Perspectives and implications. Phytomedicine 19 (2012) 253-261.

[37] Ackland, ML, Van de Waarsenburg, S, Jones, R. Synergistic antiproliferative action of the flavonols quercetin and kaempferol in cultured human cancer cell lines. In Vivo 19 (2005) 69-76.

[38] Mertens-Talcott, SU, Percival, SS. Ellagic acid and quercetin interact synergistically with resveratrol in the induction of apoptosis and cause transient cell cycle arrest in human leukemia cells. Cancer Lett. 218 (2005) 141-151. 

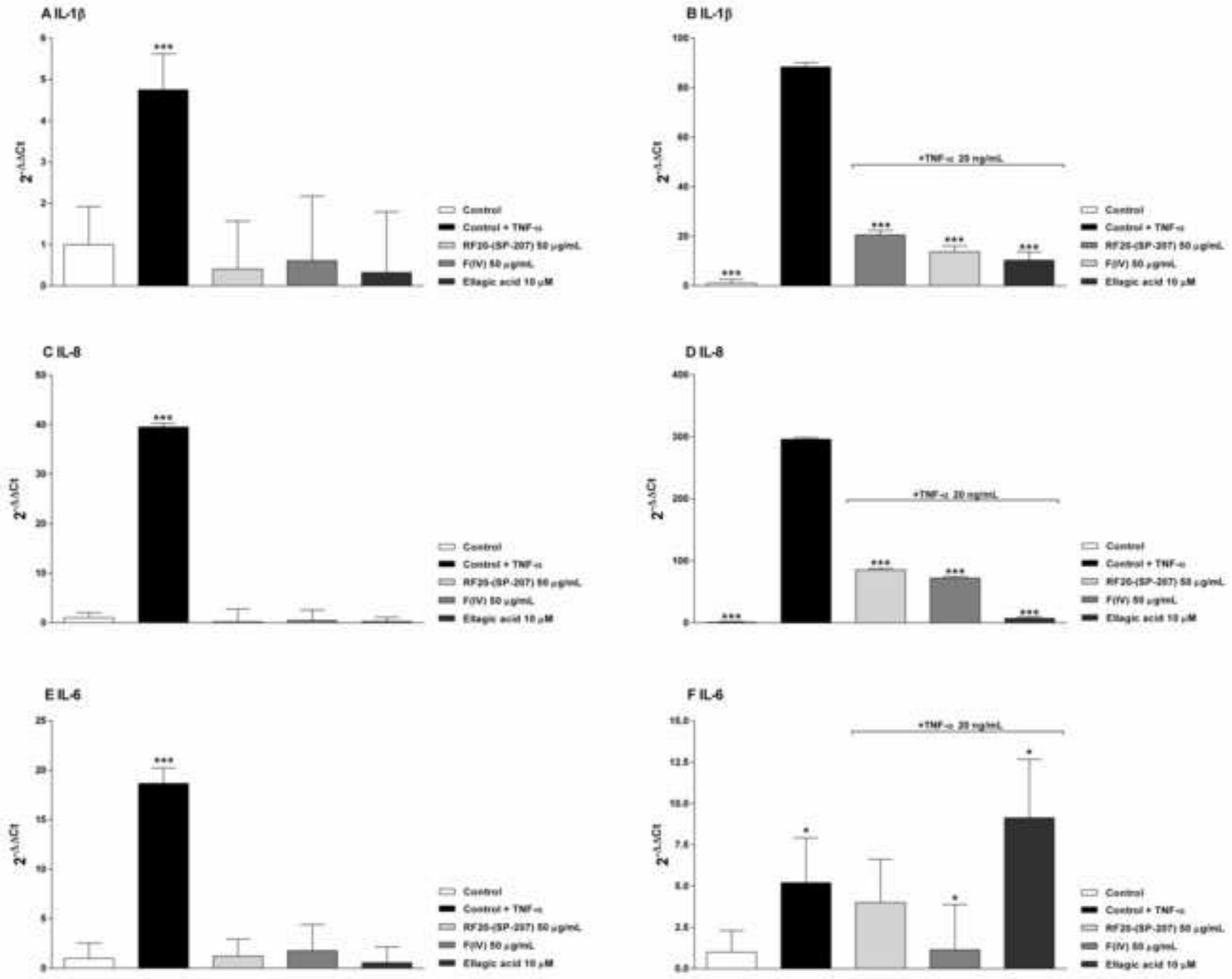

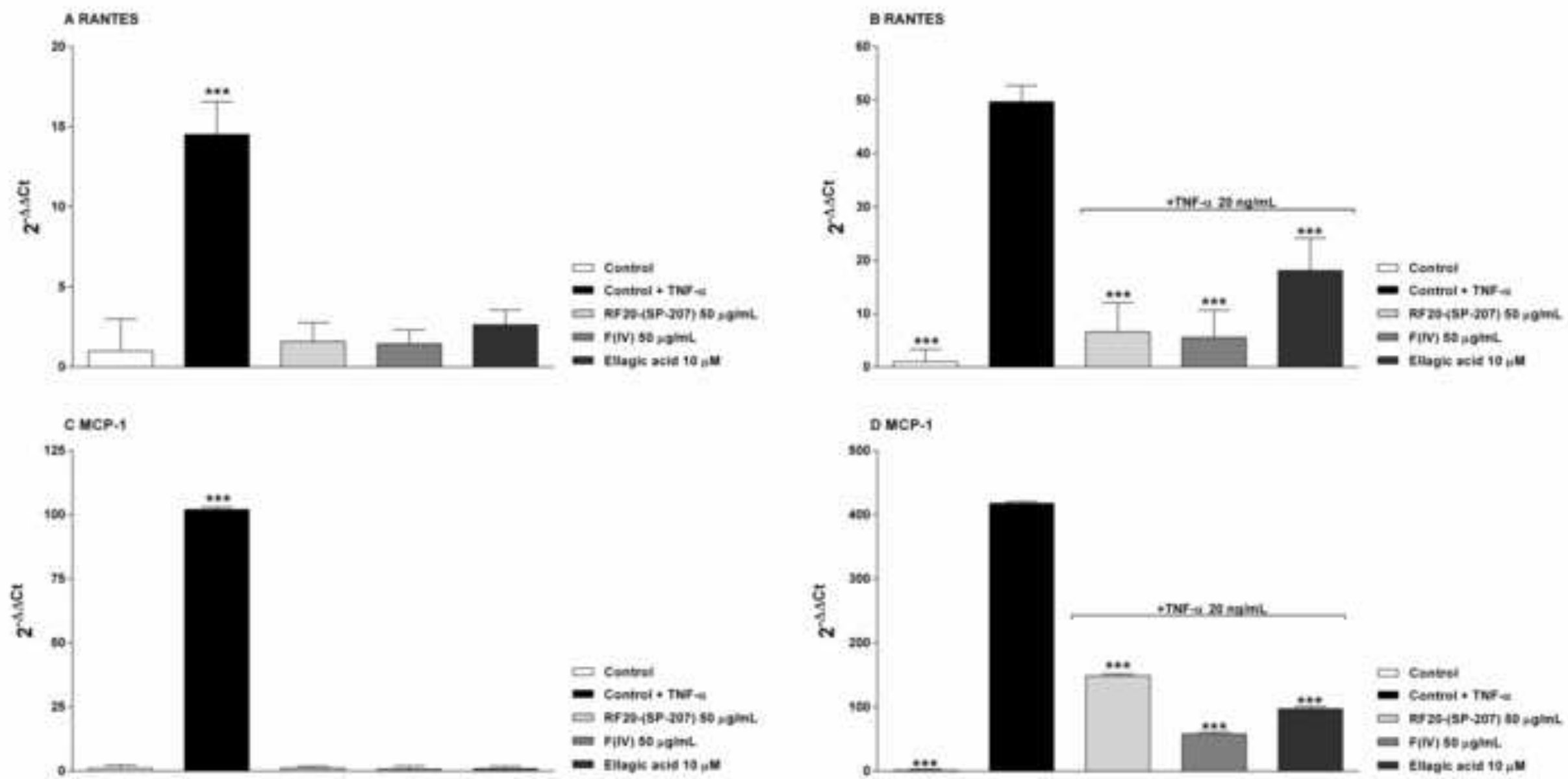
A IL -8

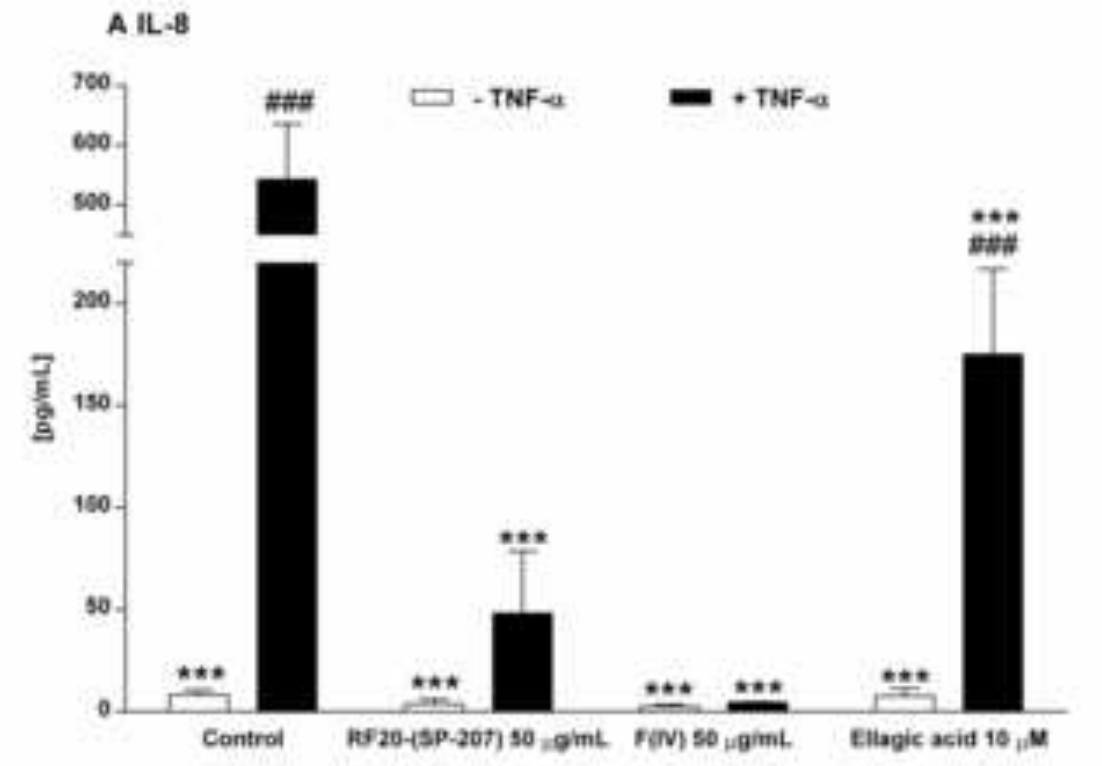

B RANTES

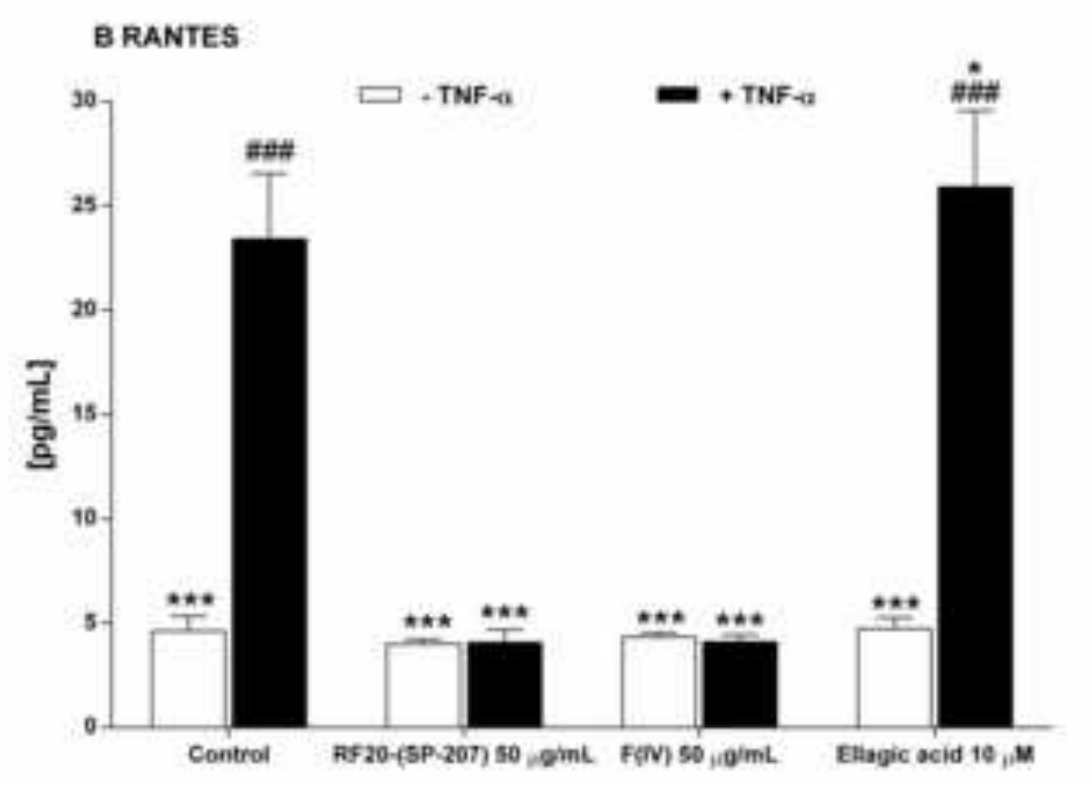

C MCP-1

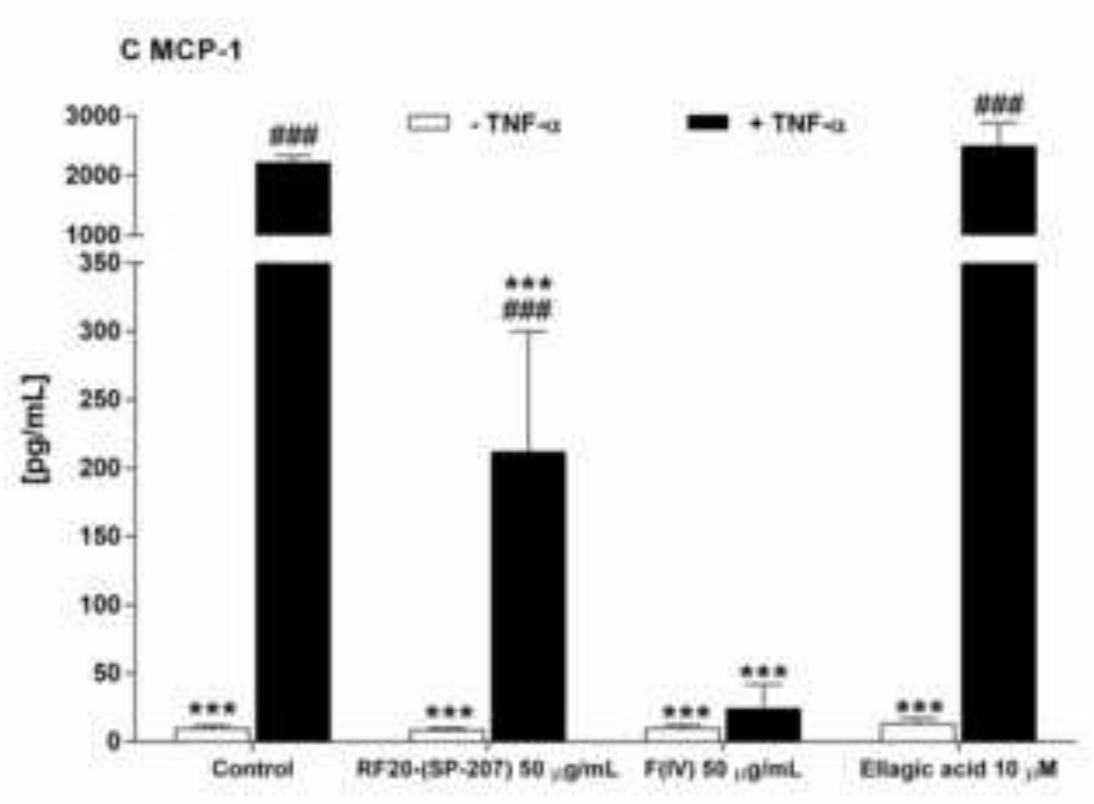

Figure 
Rosa damascena

water steam

distillation

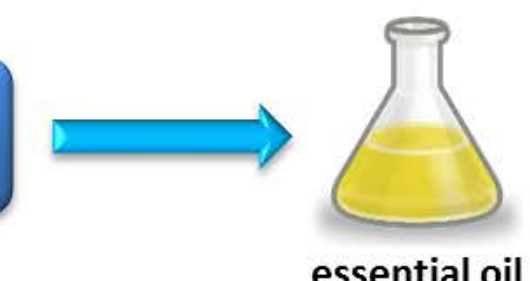

waste water

Recovery process using

Sepabead resins (SP-207)

polyphenol-
depleted fraction
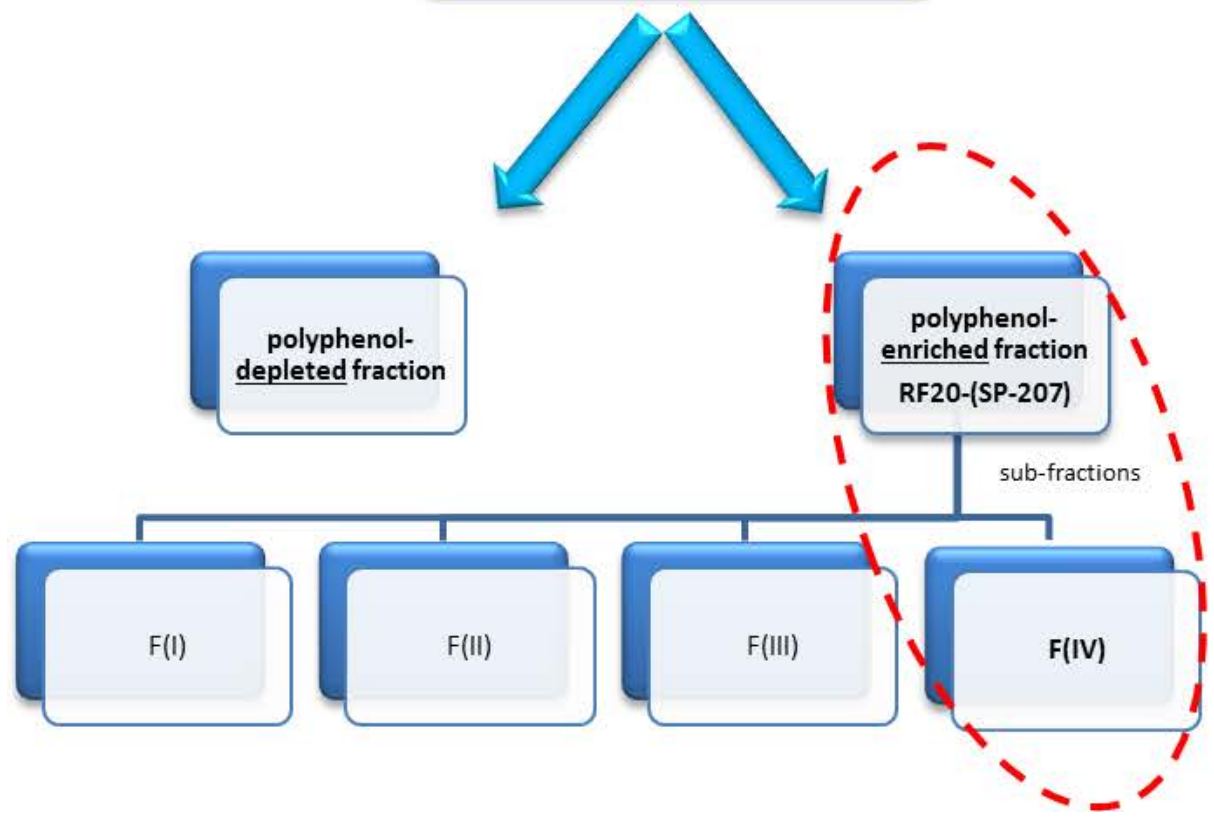

$\mathrm{HaCaT}$

cellular

protein secretion $\downarrow$ keratinocytes

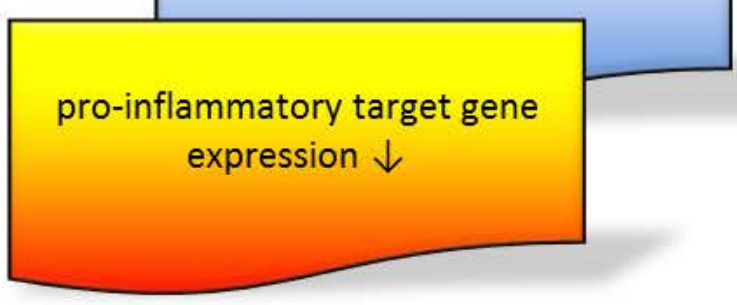

